\title{
Six Weeks of Massage Therapy Produces Changes in Balance, Neurological and Cardiovascular Measures in Older Persons
}

\author{
JoEllen M. Sefton, PhD, A.T.C., C.M.T., ${ }^{*}$ Ceren Yarar, PhD, P.T., ${ }^{1}$ Jack W. Berry, PhD ${ }^{2}$ \\ ${ }^{1}$ Neuromechanics Research Laboratory, Department of Kinesiology, Auburn University, Auburn, AL, \\ ${ }^{2}$ Department of Psychology, Samford University, Birmingham, AL, USA
}

Objectives: Falls in older adults represent a primary cause of decreased mobility and independence, increased morbidity, and accidental death. Research and clinical reports indicate that therapeutic massage (TM) may positively influence suggested causative factors. The second in a two-part study, this project assessed the effects of six weeks of TM treatment on balance, nervous system, and cardiovascular measures in older adults.

Design: A randomized controlled trial assessed the effects of six weekly 60-minute sessions of TM on balance, cardiovascular, and nervous system measures. Thirty-five volunteers (19 male and 16 female; ages $62.9 \pm 4.6$ ) were randomly assigned to relaxation control or TM groups. A $2 \times 4$ [treatment condition $X$ time (week 1 and 6 )] mixed factorial experimental design was utilized for cardiovascular/balance variables assessed at pretreatment baseline, immediate post-treatment, and 20- and 60-minutes post-treatment; nervous system measures were assessed only at pretreatment and at 60-minute follow-up $(2 \times 2$ mixed design $)$. Longterm benefits were assessed by comparing the TM and control groups on pretreatment baseline measures at week six and a follow-up assessment at week seven $(2 \times 3$ mixed design $)$.

Setting: Laboratory

Intervention: Six weekly 60-minute, full-body TM.

Outcome Measures: Postural control/cardiovascular measures were assessed weeks one, six, and seven; pretreatment and immediate, 20- and 60minutes post-treatment. Motoneuron pool excitability was assessed pretreatment and 60 minutes post-treatment.

Results: The TM group showed significant differences relative to controls in cardiovascular and displacement area/velocity after the week six session, with decreasing blood pressure and increasing stability over time from immediate post-TM to 60 minutes post-TM. The TM group revealed lower H-max/M-max ratios 60-minutes post-treatment. Long-term differences between the groups were detected at week seven in displacement area/velocity and systolic blood pressure.
Conclusions: Results suggest six weeks of TM resulted in immediate and long-term improvements in postural stability and blood pressure, compared to a controlled condition.

KEYWORDS: falls, postural control, blood pressure, heart rate, sensorimotor

\section{INTRODUCTION}

Falls occur in one-third of all adults over 65 years old, often leading to decreased independence and mobility and increased morbidity ${ }^{(1)}$, as well as to increased associated health care costs that are expected to reach $\$ 32$ billion by $2020^{(2)}$. While extensive research has been completed to understand the cause and possible interventions for this issue ${ }^{(3-12)}$, options need to be developed which will provide older adults with treatments that can help them stay active, healthy, and independent long into their senior years. A nonpharmaceutical intervention is especially important, considering the cost, interactions, and side-effects of the multiple medications seniors often require.

Influence of the visual system is thought to be a primary factor in falls in older individuals ${ }^{(13-16)}$. However, balance impairments ${ }^{(17)}$, cardiovascular $^{(18)}$, and neurological factors ${ }^{(19-20)}$ are reportedly involved in falls in this population. Postural instability may be increased by compensation for muscle imbalances, pain, current or prior musculoskeletal injury, excessive cocontractions, or inappropriate muscle activity ${ }^{(16,21-24)}$. With these factors in mind, a few studies have assessed balance training, exercise, yoga, and other interventions with inconclusive results ${ }^{(25-26)}$.

If therapeutic massage (TM) can restore muscle balance and function, restore appropriate activation, decrease spasms, correct postural imbalances, or improve gait or movement confidence, it may have a beneficial effect on postural stability. TM has been shown to influence blood flow, motoneuron pool excitability, muscle activation, and joint range of 
motion $^{(27-32)}$, suggesting that TM may have an indirect effect on postural control. Moreover, as clinicians we are trained to be aware of possible instability immediately after a TM session, which may be due to decreased blood pressure, blood glucose levels, changes in relaxation state, and other factors. We have seen this effect in our clients; however, no research to date has investigated the possible decrease in postural stability immediately following treatment, or if stability improves with time after the treatment is complete. The clinical evidence combined with the research to date suggests that TM should be investigated as a possible intervention to improve postural stability. Clearly, the population most benefiting from improved postural stability would be our older adults.

Most studies have assessed the effects of a single treatment session. However, understanding the long-term effects of regular treatments is critical to the development of safe and effective intervention protocols.

In a related study, we described the short-term effects of TM for the week one session. In the present paper, we examine whether the short-term benefits of MT found at week one were replicated in the final week six session. In addition, we examine whether TM had long-term benefits by comparing the TM and control groups at week six and a follow-up assessment at week seven (both adjusted for week one baseline measures). We hypothesized that six weeks of TM treatments would produce: 1) an immediate increase in instability; 2) increasing stability and decreased cardiovascular measures over time; and 3) improved long-term stability and cardiovascular functioning by week six continuing at week seven. If TM is found to improve balance, it could be utilized as a safe and nonpharmacological preventative intervention to decrease falls in older populations.

\section{METHODS}

\section{Experimental Design}

For the six week data, a $2 \times 4$ [treatment condition $\mathrm{X}$ time (weeks)] mixed factorial experimental design for cardiovascular and balance variables was utilized. Independent variables were treatment with two levels (control, TM) and time with four levels (pretreatment baseline, immediate post-treatment, 20-minute posttreatment, and 60-minute post-treatment). Dependent variables included balance, heart rate, and systolic and diastolic blood pressure. Motoneuron pool excitability measures were assessed only at pretreatment and at 60 -minute follow-up $(2 \times 2$ mixed design $)$. The testing occurred during the $1 \mathrm{st}$, 6th, and 7 th weeks only. Week seven was follow-up only, with no treatment and only one testing time point (Figure 1). Sample size calculations were conducted a priori, based on power considerations for the linear mixed model growth curve analyses. Minimum sample size for detecting treatment effects were determined using the Hedeker, Gibbons, and Waternaux method ${ }^{(33)}$. This approach estimates sample sizes for multilevel modeling of longitudinal data with a two-group treatment effect.

\section{Participants}

Thirty-five volunteers participated (19 male and 16 female; ages $62.9 \pm 4.6)$. As with study one ${ }^{(34)}$, participants were recruited through the use of brochures and posters in area physicians' offices, fitness facilities, libraries, stores, and by word of mouth. Inclusion criteria included individuals aged 50-69, with no history of a chronic disease that affects balance, cardiovascular health, or nervous system function,

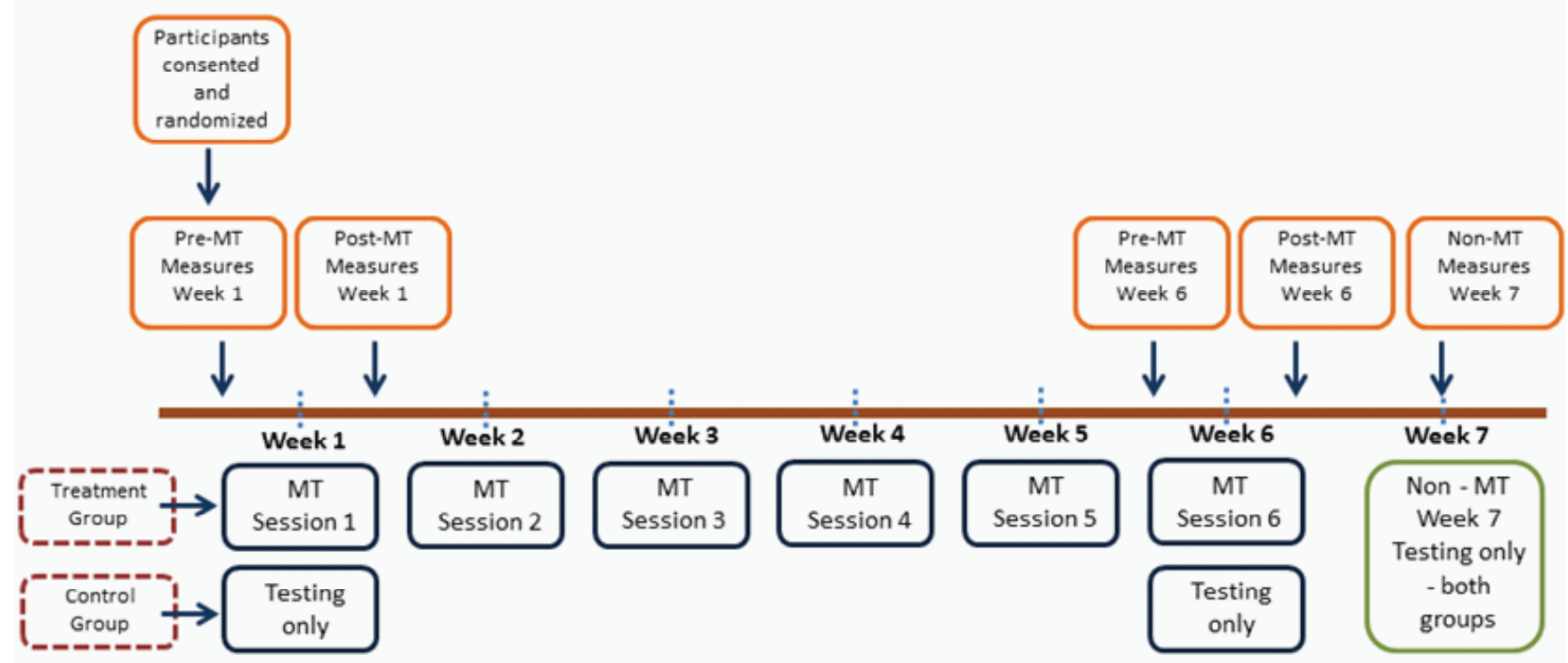

FIGURE 1. Diagram of study design and data collection time points. 
or arteriosclerosis, atherosclerosis, rheumatoid arthritis, diabetes, prior cancers, systemic disease, kidney disease, vestibular conditions, stroke, or any acute disease or illness causing a significant fever $\left(>101.5^{\circ} \mathrm{F}\right)$, any contagious disease, an unstable health condition, or currently taking medications such as blood thinners, or any drug that affects the muscles or nerves, or influences balance. Information on regular physical activity was collected, but was not an inclusion or exclusion factor. Exclusion criteria included medications/illness affecting the measures or preventing participation in TM. Participants were randomly assigned to the control/treatment groups after signing written informed consent. All procedures were approved by the Institutional Review Board.

\section{Intervention}

The treatment group received a 60-minute fullbody TM (Table 1) using massage gel (Biotone Therapy Products, San Diego, CA, USA). Three nationally certified, state licensed Massage Therapists with 3-15 years of general experience were trained in the TM protocol by the study PI to standardize treatments, with normal individual variations between treatments and sessions, providing a more clinically applicable result. The relaxation control group rested quietly in the TM room instead of receiving treatment. Participants were requested not to reveal their treatment group to the testing investigator, who was blinded to the treatment condition. Testing occurred at the same time each day, immediately prior to, and after, the TM.

\section{Assessments}

Assessments were conducted as described in part one of this study ${ }^{(34)}$.

\section{Static and functional balance}

Center of pressure (COP) measures were completed using a computerized balance platform (AccuSway Force Plate, Advanced Medical Technology, Inc., Watertown, MA, USA) and balance Clinic software (Advanced Mechanical Technology, Inc. Watertown, MA, USA). Sampling occurred at $100 \mathrm{~Hz}$ using a low-pass, fourth-order Butterworth filter with the cutoff frequency set at $5 \mathrm{~Hz}$. Participants completed four stance conditions on the force platform - two for static balance (eyes-open, double-leg stance and eyes-closed, double-leg stance) and two for functional balance (eyes-open single-leg stance and eyes-closed single-leg stance, Figure 2(a) and (b). Each stance condition was sampled three times, for 20 seconds, with 30-seconds rest between sessions. Averages of the rectangular displacement area and average displacement velocity $\left(\mathrm{V}_{\mathrm{Avg}}\right)$ were used as the primary outcome measures.

\section{Motoneuron pool excitability (Hoffmann Reflex, H-reflex)}

Electrodes were applied on the dominant extremity, as previously described ${ }^{(35)}$. Briefly, the skin was prepared and recording electrodes were placed on the soleus muscle, the stimulating electrode over the posterior tibial nerve in the popliteal fossa, the dispersal pad on the ipsilateral suprapatellar region, and the ground electrode over the ipsilateral lateral malleolus. The double-leg soleus maximum H-reflex $\left(\mathrm{H}_{\max }\right)$ and maximum $\mathrm{M}$-wave $\left(\mathrm{M}_{\max }\right)$ were determined. Electromyographic output (MP 150, Biopac Systems Inc. Goleta, CA) was differentially amplified 500-2000 times, and filtered at $10-1000 \mathrm{~Hz}$ bandwidth. The peak-to-peak amplitude of $\mathrm{H}_{\max }$ and $\mathrm{M}_{\max }$ was recorded during the pre- and postintervention periods. An average of seven stimulation trials were calculated for $\mathrm{H}_{\max } / \mathrm{M}_{\max }$ ratio which was used as a measure of soleus $\alpha$-motoneuron pool excitability.

\section{Paired-reflex depression protocol (PRD)}

A PRD protocol was used to assess the influence of activation history on motoneuron pool excitability in a double- and single-leg stance. This allows the assessment of changes that occurs before the synapse. PRD was measured ${ }^{(36)}$ as the percent depression of the conditioned H-reflex peak (two equal-magnitude pulses separated by $80 \mathrm{msec}$ ) relative to the nonconditioned H-reflex peak. The test stimulus standardized at $35 \%$ of the soleus $M_{\max }{ }^{(37)}$. Average of the seven trials was calculated and used for analysis.

\section{Recurrent inhibition (RI) protocol}

An RI protocol was used as previously described ${ }^{(38)}$ to assess postsynaptic modulation of soleus motoneuron pool excitability. PRD looks at changes before the synapse, while RI assesses changes after the synapse that are primarily due to the effect of Renshaw cell activity. RI was calculated as the percent difference between the amplitude of the H-reflex with and without the conditioning stimulus. The conditioning stimulus was $25 \%$ of the soleus $M_{\max }$, followed $10 \mathrm{msec}$ later by a second stimulus set at $M_{\max }$. Average of the seven trials was calculated and used for analysis.

\section{Heart rate and blood pressure}

An automatic digital blood pressure monitor (Model: UA-787, A\&D Engineering Inc, San Jose, California) was used to measure heart rate and blood pressure. Systolic/diastolic blood pressures and heart rate were recorded after resting quietly; two recordings were taken with 5 minutes between measurements. Heart rate and blood pressure were initially recorded subsequent to static and functional balance tests. Midway in the study, it was determined the participants' frustration with the eyes-closed single-leg stance condition may be confounding the results and measurements were moved to the beginning of each testing session. 
TABLE 1. Standardized 60-minute TM Protocol ${ }^{(34)}$

\section{Bilaterally (supine):}

Gliding (effleurage), general neck/shoulders, spread cream

Head and face - without massage cream

Gentle stroking, pressure points, kneading and scalp scrub

2 minutes

Kneading (petrissage); neck/shoulders

Friction-gliding

Kneading (petrissage); upper trapezius, levator scapula

2 minutes

The following strokes will be done on one side, then the other:

Friction - circular; beginning at the occiput, moving lateral to mastoid process

Friction - gliding

Direct pressure (trigger point); from occiput, moving lateral to mastoid process

Friction - circular; from occiput, moving lateral to mastoid process

The following strokes will be done bilaterally:

Kneading (petrissage); upper trapezius, levator scapula, scalenes

Friction - circular; scalenes

Friction - gliding, stripping; scalenes (using lighter pressure on older individuals is recommended as per general MT guidelines)

Direct pressure (trigger point); trapezius, levator scapula, scalene (see pressure comment above)

Gliding (effleurage); general neck/shoulders

1 minute

\section{Arm (left, supine):}

Gliding (effleurage), over anterior/posterior arm, spread cream

Shaking at the glenohumeral joint (supporting the wrist, gently lift the arm and shake providing movement at the glenohumeral joint)

Kneading (petrissage); over lower, upper arm and hand

\section{Leg (left, then right; supine):}

Gliding (effleurage), over anterior leg, spread cream

Kneading (petrissage); over lower, upper leg

Gliding, kneading of dorsum of foot, gentle traction of toes and movement of phalanges

\section{Arm (right, supine):}

Repeat as described under left arm above

Have participant roll over and position prone with bolster under ankles, insure comfort

\section{Leg (right, then left; prone)}

Gentle compressions of gluteal muscles, and shaking of leg

Gliding (effleurage), over posterior leg, spread cream

Kneading (petrissage); over lower, upper leg

Gliding, kneading of bottom of foot, gentle friction, flex knee, lift whole leg and gently shake providing motion the hip

Repeat on left leg

\section{Back (prone):}

Gliding (effleurage), over back, spread cream

Kneading (petrissage) over back

Transverse or circular friction over erector spinae

15 minutes

Kneading, and trigger point work as needed around scapula, and along trapezius

Finish - gliding (effeurage), shaking, closure, breathing

3 minutes

Within these guidelines, the Therapist adapted the specific therapeutic decisions to their experience and the comfort/needs of the client. 

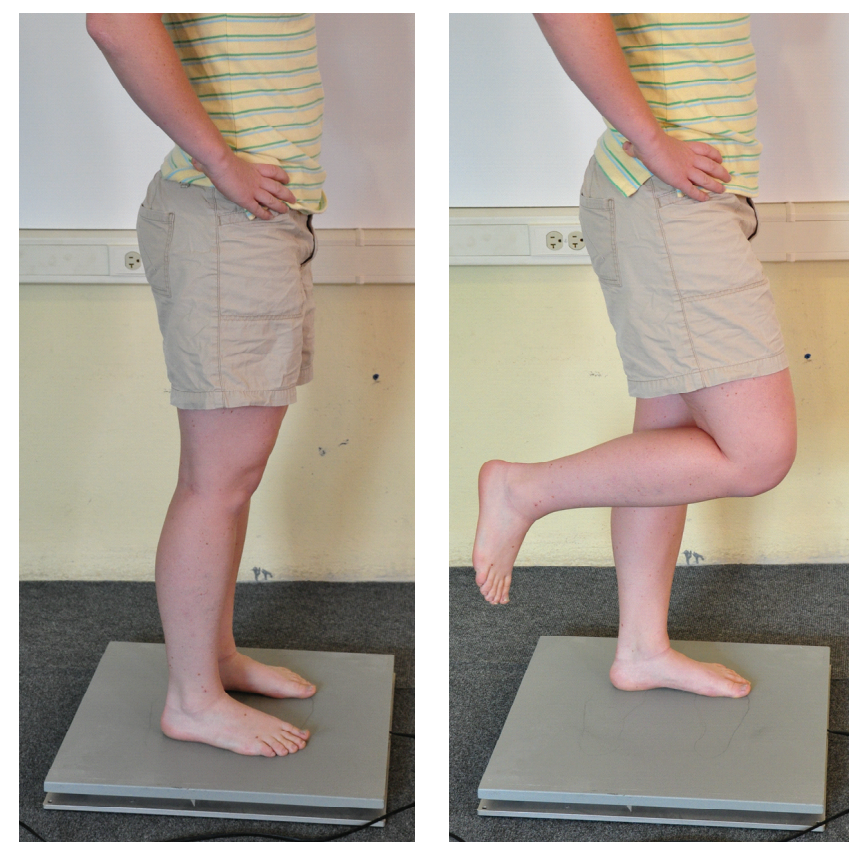

(a)

(b)

FIGURE 2. Double- and single-legged stance. (a) A double-leg stance for the static balance test and H-reflex testing was assumed with two feet placed shoulder width apart and with hands on the hips. (b) A single-leg stance for the functional balance test and H-reflex testing was assumed with the non-stance extremity standardized in a position of 30 degrees of hip flexion and 90 degrees of knee flexion, with the ankle relaxed.

A statistical analysis was conducted to determine if an effect of testing order was present. Average of the two trials for systolic/diastolic blood pressures and heart rate were calculated and used for analysis.

\section{Statistical Analysis}

Analysis of covariance (ANCOVA) was used to compare the treatment and control groups on immediate post-treatment postural control and cardiovascular measures, with pretreatment baseline measures used as covariates. In these analyses, higher baseline-adjusted post-treatment means on postural control outcomes in the TM group would suggest that TM produced initial instability in the treatment group relative to controls. Assessment for postintervention balance and cardiovascular changes across time (immediate post-treatment, 20-, and 60-minutes post-treatment) were evaluated using linear growth curve modeling for predicting post-treatment outcomes from treatment condition, time, and the interaction of treatment with time, with pretreatment baseline measures used as covariates [two-tailed tests; $p<.05$ significance level; linear mixed models module of SPSS (version 19, IBM SPSS Statistics, Chicago, IL, USA)]. In the growth curve analyses, a significant interaction of treatment with time provides evidence for different treatment post-treatment outcome trajectories for the MT and control groups. Because motoneuron pool variables were assessed only pretreatment and 60 minutes post-treatment, ANCOVA (rather than growth curve analysis) was used to compare groups on motoneuron pool excitability measures at the 60-minute follow-up assessment, adjusting for pretreatment baseline. Finally, Pearson's correlations comparisons were used to assess potential relationships between the H-reflex and postural control variables. Past studies have suggested that H-reflex changes are related to changes in postural control $^{(11,13)}$. While correlations do not suggest cause and effect, a significant relationship does indicate that postural control and H-reflex measures do bear some connection that may be worth further investigation.

\section{Long-Term Effects of Treatment}

The analyses described above examined the effects of a single session of TM (at week 6, the final session of the 6-week intervention protocol) on postsession outcomes. We also examined whether the intervention had long-term effects on resting-level (baseline) outcomes assessed at week 6 (baseline prior to TM session) and week 7 (an assessment-only follow-up with no TM session provided). To test the long-term effects of MT, analysis of covariance (ANCOVA) was used to compare the MT and control groups on week 6 pretreatment baseline outcome and on week 7 (assessment only) outcomes, using week 1 baseline measures as covariates. In these analyses, significant differences between the TM and control groups on adjusted means at week 6 or week 7 (adjusted for week 1 baselines) would indicate differential longterm treatment effects on outcomes.

\section{RESULTS}

Descriptive statistics for all outcomes are presented in Table 2(a-c). Tables 3-6 present the results for statistical tests of short-term, postsession effects of TM in week six. Table 7 presents week six correlations between $\mathrm{H}$-reflex variables and postural control. Table 8 presents the ANCOVA analyses testing the long-term effects of TM on presession baseline measures at week six and on week seven measures.

\section{Immediate Treatment Effects: Week 6 Session}

The immediate pre- to post-TM effects at week six on balance and cardiovascular variables (Table 3 ) were assessed via ANCOVA in order to identify any increased instability resulting from TM. Although the TM group had higher adjusted means on most balance and cardiovascular variables (indicating some increase in instability), only the effect for diastolic blood pressure was statistically significant $(\mathrm{F}=9.35$, $p<.01)$. 
Table 2. (a) Descriptive Statistics for Pre- and Postcondition Cardiovascular Measures in the Treatment and Control Groups [Mean (Standard Deviation)]

\begin{tabular}{|c|c|c|c|c|c|c|c|c|c|c|}
\hline Variable & $\begin{array}{c}6^{\text {th }} \text { week } \\
\text { pre } \\
(T M)\end{array}$ & $\begin{array}{c}6^{\text {th }} \text { week } \\
\text { pre } \\
\text { (C) }\end{array}$ & $\begin{array}{c}6^{\text {th }} \text { week } \\
0 \text { min. } \\
\text { post } \\
(T M)\end{array}$ & $\begin{array}{c}6^{\text {th }} \text { week } \\
0 \text { min. } \\
\text { post } \\
(C)\end{array}$ & $\begin{array}{c}6^{\text {th }} \text { week } \\
20 \text { min. } \\
\text { post } \\
\text { (TM) }\end{array}$ & $\begin{array}{c}6^{\text {th }} \text { week } \\
20 \text { min. } \\
\text { post } \\
(C)\end{array}$ & $\begin{array}{c}6^{\text {th }} \text { week } \\
60 \text { min. } \\
\text { post } \\
(T M)\end{array}$ & $\begin{array}{c}6^{\text {th }} \text { week } \\
60 \text { min. } \\
\text { post } \\
(C)\end{array}$ & $\begin{array}{c}7^{\text {th }} \text { week } \\
\text { (TM) }\end{array}$ & $\begin{array}{c}7^{\text {th }} \text { week } \\
\text { (C) }\end{array}$ \\
\hline
\end{tabular}

$\begin{array}{lllllllllll}\mathrm{HR} & 76.2(12.3) & 67.5(12.6) & 68.9(10.2) & 63.4(11.4) & 69.1(9.2) & 61.7(10.7) & 69.6(8.7) & 62.3(13.0) & 71.2(10.7) & 68.6(16.1)\end{array}$ SBP $\quad 127.1(21.8) 130.3(12.9) 129.8$ (13.7) 130.5 (15.8) $127.0(15.0) 132.3(24.7) 131.0(17.4) 125.8$ (17.7) $121.7(13.8) 136.0(22.9)$ $\begin{array}{lllllllllll}\mathrm{DBP} & 75.4(14.0) & 79.0(7.3) & 79.8(13.6) & 76.5(11.1) & 77.6(11.5) & 77.5(11.9) & 76.9(11.9) & 77.3(9.9) & 76.3(10.4) & 78.7(12.7)\end{array}$

$\mathrm{TM}=$ therapeutic massage group; $\mathrm{C}=$ control group $\mathrm{HR}=$ heart rate; $\mathrm{SBP}=$ systolic blood pressure; $\mathrm{DBP}=$ diastolic blood pressure.

TABle 2. (b) Descriptive Statistics for Pre- and Postcondition Postural Control Measures in the Treatment and Control Groups [Mean (Standard Deviation)]

\begin{tabular}{|c|c|c|c|c|c|c|c|c|c|c|}
\hline Variable & $\begin{array}{c}6^{\text {th }} \text { week } \\
\text { pre } \\
(T M)\end{array}$ & $\begin{array}{c}6^{\text {th }} \text { week } \\
\text { pre } \\
\text { (C) }\end{array}$ & $\begin{array}{c}6^{\text {th }} \text { week } \\
0 \text { min. } \\
\text { post } \\
\text { (TM) }\end{array}$ & $\begin{array}{c}6^{\text {th }} \text { week } \\
0 \text { min. } \\
\text { post } \\
\text { (C) }\end{array}$ & $\begin{array}{c}6^{\text {th }} \text { week } \\
20 \text { min. } \\
\text { post } \\
(T M)\end{array}$ & $\begin{array}{c}6^{\text {th }} \text { week } \\
20 \text { min. } \\
\text { post } \\
\text { (C) }\end{array}$ & $\begin{array}{c}6^{\text {th }} \text { week } \\
60 \text { min. } \\
\text { post } \\
(T M)\end{array}$ & $\begin{array}{c}6^{\text {th }} \text { week } \\
60 \text { min. } \\
\text { post } \\
\text { (C) }\end{array}$ & $\begin{array}{c}7^{\text {th }} \text { week } \\
\text { (TM) }\end{array}$ & $\begin{array}{c}7^{\text {th }} \text { week } \\
\text { (C) }\end{array}$ \\
\hline $\begin{array}{l}\text { Area Rect. } \\
\text { EODL }\end{array}$ & $0.47(0.52)$ & $0.83(1.24)$ & $1.20(2.67)$ & $0.67(0.62)$ & $0.80(1.41)$ & $0.68(1.07)$ & $0.46(0.36)$ & $0.58(0.75)$ & $0.26(0.13)$ & $1.74(2.34)$ \\
\hline $\begin{array}{l}\text { Area Rect. } \\
\text { ECDL }\end{array}$ & $0.79(0.65)$ & $1.25(1.20)$ & $1.14(0.87)$ & $0.79(0.48)$ & $0.80(0.77)$ & $0.82(0.35)$ & $0.71(0.38)$ & $0.92(0.69)$ & $0.55(0.22)$ & $1.35(1.06)$ \\
\hline $\begin{array}{l}\text { Area Rect. } \\
\text { EOSL }\end{array}$ & $1.51(1.26)$ & $1.23(1.00)$ & $1.62(1.57)$ & $1.08(0.68)$ & $1.08(0.44)$ & $1.51(1.86)$ & $1.01(0.39)$ & $1.73(2.67)$ & $1.36(1.20)$ & $1.58(0.99)$ \\
\hline $\begin{array}{l}\text { Area Rect. } \\
\text { ECSL }\end{array}$ & $5.04(2.71)$ & $3.90(1.07)$ & $4.84(2.74)$ & $4.80(3.95)$ & $5.09(1.78)$ & $5.11(5.01)$ & $5.16(2.08)$ & $5.19(2.45)$ & $4.63(2.00)$ & $3.02(0.98)$ \\
\hline $\begin{array}{l}\mathrm{V}_{\mathrm{Avg}} \\
\text { EODLL }\end{array}$ & $0.59(0.30)$ & $0.86(0.74)$ & $0.69(0.69)$ & $0.51(0.06)$ & $0.70(0.68)$ & $0.48(0.07)$ & $0.50(0.09)$ & $0.70(0.69)$ & $0.48(0.07)$ & $1.36(1.11)$ \\
\hline $\begin{array}{l}\mathrm{V}_{\mathrm{Avg}} \\
\mathrm{ECDL}\end{array}$ & $0.83(0.40)$ & $1.06(0.66)$ & $0.88(0.56)$ & $0.70(0.14)$ & $0.72(0.28)$ & $0.83(0.41)$ & $0.67(0.17)$ & $0.79(0.45)$ & $0.73(0.23)$ & $1.11(0.55)$ \\
\hline $\begin{array}{l}\mathrm{V}_{\text {Avg }} \\
\text { EOSL }\end{array}$ & $1.89(0.83)$ & $1.59(0.48)$ & $1.60(0.79)$ & $1.33(0.55)$ & $1.35(0.36)$ & $1.40(0.42)$ & $1.26(0.36)$ & $1.54(0.88)$ & $1.77(0.78)$ & $1.89(0.58)$ \\
\hline $\begin{array}{l}\mathrm{V}_{\text {Avg }} \\
\text { ECSL }\end{array}$ & $2.37(1.40)$ & $2.81(2.53)$ & $2.39(1.20)$ & $2.23(1.32)$ & $2.41(1.18)$ & $2.58(1.66)$ & $2.28(1.13)$ & $2.74(1.06)$ & $2.44(1.39)$ & $1.85(0.85)$ \\
\hline
\end{tabular}

$\mathrm{TM}=$ therapeutic massage group; $\mathrm{C}=$ control group; Area Rect = area rectangular; $\mathrm{V}_{\text {avg }}=$ average velocity; EODL = eyes-open double-leg; ECDL = eyes-closed double-leg; EOSL = eyes-open single-leg; ECSL = eyes-closed single-leg.

Table 2. (c) Descriptive Statistics for Pre- and Postcondition Reflex Measures in the Treatment and Control Groups [Mean (Standard Deviation)]

\begin{tabular}{|c|c|c|c|c|c|c|c|c|c|c|}
\hline Variable & $\begin{array}{c}6^{\text {th }} \text { week } \\
\text { pre } \\
(T M)\end{array}$ & $\begin{array}{c}6^{\text {th }} \text { week } \\
\text { pre } \\
\text { (C) }\end{array}$ & $\begin{array}{c}6^{\text {th }} \text { week } \\
\text { 0 min. } \\
\text { post } \\
(T M)\end{array}$ & $\begin{array}{c}6^{\text {th }} \\
0 \text { min. } \\
\text { week } \\
\text { post }(C)\end{array}$ & $\begin{array}{c}6^{\text {th }} \text { week } \\
20 \text { min. } \\
\text { post } \\
(T M)\end{array}$ & $\begin{array}{c}6^{\text {th }} \text { week } \\
20 \text { min. } \\
\text { post } \\
(C)\end{array}$ & $\begin{array}{c}6^{\text {th }} \text { week } \\
60 \text { min. } \\
\text { post } \\
(T M)\end{array}$ & $\begin{array}{c}6^{\text {th }} \text { week } \\
60 \text { min. } \\
\text { post } \\
(C)\end{array}$ & $\begin{array}{c}7^{\text {th }} \text { week } \\
\text { (TM) }\end{array}$ & $\begin{array}{c}7^{\text {th }} \text { week } \\
\text { (C) }\end{array}$ \\
\hline $\mathrm{H}_{\max } / \mathrm{M}_{\max }$ & $0.27(0.16)$ & $0.26(0.16)$ & & & & & $0.19(0.11)$ & $0.29(0.22)$ & $0.24(0.12)$ & $0.20(0.13)$ \\
\hline PRD 2L & $\begin{array}{c}62.29 \\
(18.50)\end{array}$ & $\begin{array}{c}56.45 \\
(24.40)\end{array}$ & & & & & $65.3(20.40)$ & $\begin{array}{c}67.52 \\
(17.30)\end{array}$ & $\begin{array}{c}68.13 \\
(18.60)\end{array}$ & $\begin{array}{c}68.49 \\
(12.33)\end{array}$ \\
\hline RI 2L & $\begin{array}{c}55.21 \\
(29.60)\end{array}$ & $\begin{array}{c}58.40 \\
(26.40)\end{array}$ & & & & & $\begin{array}{c}56.50 \\
(20.30)\end{array}$ & $\begin{array}{c}53.12 \\
(24.50)\end{array}$ & $\begin{array}{c}78.21 \\
(10.08)\end{array}$ & $\begin{array}{c}79.44 \\
(10.77)\end{array}$ \\
\hline PRD 1L & $\begin{array}{c}62.54 \\
(24.00)\end{array}$ & $\begin{array}{c}58.68 \\
(17.30)\end{array}$ & & & & & $\begin{array}{c}67.36 \\
(18.90)\end{array}$ & $\begin{array}{c}61.83 \\
(17.50)\end{array}$ & $\begin{array}{c}71.32 \\
(17.22)\end{array}$ & $\begin{array}{c}64.62 \\
(15.33)\end{array}$ \\
\hline RI 1L & $\begin{array}{c}80.09 \\
(15.50)\end{array}$ & $\begin{array}{c}70.58 \\
(17.10)\end{array}$ & & & & & $\begin{array}{c}76.11 \\
(11.1) 0\end{array}$ & $69.09(16.40$ & $\begin{array}{c}80.17 \\
(10.29)\end{array}$ & $\begin{array}{c}72.86 \\
(16.67)\end{array}$ \\
\hline
\end{tabular}

$\mathrm{TM}=$ therapeutic massage group; $\mathrm{C}=$ control group; $\mathrm{H}_{\max }=$ maximum $\mathrm{H}$-reflex; $\mathrm{M}_{\max }=$ maximum $\mathrm{M}$-wave; $\mathrm{PRD} 2 \mathrm{~L}=$ pair reflex depression 2 leg; PRD $1 \mathrm{~L}=$ pair reflex depression 1 leg; RI $2 \mathrm{~L}=$ recurrent inhibition 2 leg; RI $1 \mathrm{~L}=$ recurrent inhibition 1 leg. 
Table 3. Analyses of Covariance Predicting Immediate Post-TM Outcomes (Adjusted for Baseline) at Week 6

\begin{tabular}{lccccc}
\hline & \multicolumn{2}{c}{ Treatment } & \multicolumn{2}{c}{ Control } & \\
\cline { 2 - 4 } & Adj.M & $S E$ & Adj.M & SE & $F$ \\
\hline Displacement Area & & & & & \\
Rect.: EODL & 1.38 & .45 & .37 & .68 & 1.51 \\
Rect.: ECDL & 1.15 & .15 & .66 & .22 & 3.16 \\
Rect.: EOSL & 1.41 & .19 & 1.21 & .29 & 0.29 \\
Rect.: ECSL & 4.85 & .49 & 4.03 & .77 & 0.77 \\
Displacement Velocity & & & & & \\
Vel.: EODL & .73 & .12 & .47 & .19 & 1.24 \\
Vel.: ECDL & .92 & .08 & .58 & .13 & 4.12 \\
Vel.: EOSL & 1.49 & .11 & 1.50 & .16 & 0.01 \\
Vel.: ECSL & 2.50 & .18 & 2.08 & .26 & 1.74 \\
Cardiovascular & & & & & \\
Systolic BP & 129.8 & 2.08 & 127.0 & 3.04 & 0.57 \\
Diastolic BP & 80.5 & 1.26 & 73.7 & 1.80 & $9.35^{b}$ \\
Heart Rate & 67.0 & 1.29 & 67.5 & 1.90 & 0.07 \\
\hline
\end{tabular}

${ }^{\mathrm{b}} p<.01$

Adj. $\mathrm{M}=$ covariate adjusted mean (baseline as covariate); $\mathrm{SE}=$ standard error; Area Rect $=$ area rectangular; EODL $=$ eyes-open double-leg; ECDL = eyes-closed double-leg; EOSL = eyes-open single-leg; ECSL = eyes-closed single-leg.

\section{Week Six Short-Term Post-Treatment Effects Across Time}

\section{Postural Control Outcomes: Displacement Areas and Velocity}

Table 4 presents the short-term effects of TM (at week six) on the trajectories of the rectangular displacement area and velocity from immediate post-TM to 60-minutes post-TM. Rectangular area of displacement had a significant treatment $\mathrm{X}$ time interaction for the eyes-closed, double-leg stance (Figure 2(a)). There was also a significant interaction for the eyes-open, single-leg condition. There were no treatment effects for area displacement in the eyes-closed, single-leg stance condition. Assessing average displacement velocity from immediately post-TM to 60 -minutes post-TM, the treatment $\mathrm{X}$ time interactions for the eyes-closed, double-leg condition, the eyes-open, single-leg condition, and eyes-closed, single-leg conditions were significant (Figure 2(b)). The significant downward trajectories in measures for these stances suggest that TM increased postural stability across these time points. The interaction for the eyes-open, double-leg stance condition only approached significance $(\mathrm{t}=-1.71, p<.10)$.

\section{Nervous System Outcomes}

Reflex variables were measured pretreatment and 60-minute post-TM. Table 5 presents the ANCOVA results, assessing the treatment effects for the reflex variables. The TM group produced a significantly lower $\mathrm{H}_{\max } / \mathrm{M}_{\text {max }}$ ratio than the control group $(\mathrm{F}=11.6, p$ $<.05$ ) at the 60-minute follow-up; there were no other significant effects. Pearson's correlations between H-reflex and balance measures revealed significant relationships in the single-leg stance (Table 6).

\section{Cardiovascular Outcomes}

Table 7 presents the short-term effects of TM (week six) on the cardiovascular variables from immediately post-TM to 60-minutes post-TM. The interaction of treatment condition with time was significant for both systolic and diastolic blood pressure. Blood pressure declined over time post-treatment for the TM group, but increased (or remained stable) for the control group (Figure 3(c)). An order variable analysis (adding an order effect to the growth models, coded 0 for balance testing first, 1 for cardiovascular testing first) found that the timing change in assessing cardiovascular measures had an effect only for systolic blood pressure $[\mathrm{B}=0.65$, $\mathrm{SE}=0.08, \mathrm{t}(29.5)=-2.14, p<.05]$, indicating lower BP for participants assessed prior to the balance assessments), but the treatment effect was unchanged for this outcome and in all cardiovascular measures.

\section{Long-Term Treatment Effects: Week Six and Seven}

\section{Postural Control Outcomes: Displacement Area and Velocity}

An ANCOVA compared the two groups on week six presession baseline and week seven displacement area and velocity measures, adjusted for week 1 baselines (Table 8). ANCOVA also compared the two groups on week seven stability measures, adjusted for week 1 baselines. There were no significant group differences at week six for any displacement outcome. By week seven, the treatment group had significantly lower displacement area and velocity in multiple conditions. There were no significant group differences for any balance measure at week seven in the eyes-closed, single-leg condition.

\section{Nervous System Outcomes}

An ANCOVA compared the two groups on week six and week seven reflex measures (Table 8). There were no significant group differences on any reflex variable. Thus, although the $\mathrm{H}_{\max } / \mathrm{M}_{\max }$ ratio showed immediate treatment effects, there was no significant difference in baseline reflex measures over the long term.

\section{Cardiovascular Outcomes}

An ANCOVA compared the two groups on week six and week seven cardiovascular measures (Table 8). There was no significant group difference in systolic blood pressure at week six, but by week seven the TM group was significantly lower. There was no significant group difference for diastolic blood 
Table 4. Fixed Effects Estimates of Postural Control Outcomes in Four Conditions: Rectangular Area of Displacement and Velocity

\begin{tabular}{|c|c|c|c|c|c|c|c|}
\hline & \multicolumn{3}{|c|}{$\begin{array}{c}\text { Short-Term: Week 6: average rectangular } \\
\text { area of displacement }\end{array}$} & & \multicolumn{3}{|c|}{$\begin{array}{l}\text { Short-Term: Week 6: average } \\
\text { displacement velocity }\end{array}$} \\
\hline & $B$ & $S E$ & $t$ & & $B$ & $S E$ & $t$ \\
\hline Rect. Area: EODL & & & & Velocity: EODL & & & \\
\hline Intercept & 0.29 & 0.44 & 0.65 & Intercept & 0.21 & 0.17 & 1.25 \\
\hline Time & -0.04 & 0.31 & 0.90 & Time & 0.09 & 0.09 & 0.96 \\
\hline Treatment & 0.63 & 0.50 & 1.25 & Treatment & 0.31 & 0.17 & $1.80+$ \\
\hline Baseline & 0.49 & 0.19 & $2.53^{\mathrm{a}}$ & Baseline & 0.31 & 0.12 & $2.54^{\mathrm{a}}$ \\
\hline Treatment $*$ Time & -0.35 & 0.37 & -0.92 & Treatment $*$ Time & -0.20 & 0.11 & $-1.71+$ \\
\hline Rect. Area: ECDL & & & & Velocity: ECDL & & & \\
\hline Intercept & 0.49 & 0.19 & $2.53^{\mathrm{a}}$ & Intercept & 0.34 & 0.12 & $2.89^{b}$ \\
\hline Time & 0.08 & 0.11 & 0.76 & Time & 0.07 & 0.06 & 1.07 \\
\hline Treatment & 0.34 & 0.20 & $1.73+$ & Treatment & 0.24 & 0.11 & $2.19^{\mathrm{a}}$ \\
\hline Baseline & 0.24 & 0.08 & $2.78^{\mathrm{b}}$ & Baseline & 0.30 & 0.07 & $4.09^{c}$ \\
\hline Treatment $*$ Time & -0.28 & 0.13 & $-2.04^{\mathrm{a}}$ & Treatment $*$ Time & -0.17 & 0.08 & $-2.14^{\mathrm{a}}$ \\
\hline Rect. Area: EOSL & & & & Velocity: EOSL & & & \\
\hline Intercept & 0.76 & 0.44 & $1.71+$ & Intercept & 0.71 & 0.22 & $3.22^{\mathrm{b}}$ \\
\hline Time & 0.38 & 0.24 & 1.60 & Time & 0.11 & 0.09 & 1.13 \\
\hline Treatment & 0.27 & 0.48 & 0.56 & Treatment & 0.14 & 0.19 & 0.73 \\
\hline Baseline & 0.25 & 0.15 & 1.65 & Baseline & 0.36 & 0.09 & $3.82^{b}$ \\
\hline Treatment $*$ Time & -0.60 & 0.28 & $-2.12^{\mathrm{a}}$ & Treatment $*$ Time & -0.27 & 0.11 & $-2.27^{\mathrm{a}}$ \\
\hline Rect. Area: ECSL & & & & Velocity: ECSL & & & \\
\hline Intercept & 2.39 & 0.72 & $3.32^{\mathrm{b}}$ & Intercept & 0.84 & 0.34 & $2.43^{\mathrm{a}}$ \\
\hline Time & 0.43 & 0.46 & 0.92 & Time & 0.27 & 0.12 & $2.18^{\mathrm{a}}$ \\
\hline Treatment & 1.33 & 0.74 & $1.80+$ & Treatment & 0.56 & 0.33 & $1.71+$ \\
\hline Baseline & 0.24 & 0.09 & $2.58^{\mathrm{a}}$ & Baseline & 0.46 & 0.08 & $5.89^{c}$ \\
\hline Treatment $*$ Time & -0.33 & 0.55 & -0.60 & Treatment $*$ Time & -0.34 & 0.15 & $-2.30^{\mathrm{a}}$ \\
\hline
\end{tabular}

${ }^{a} p<.05$

${ }^{\mathrm{b}} p<.01$

c $p<.001$

$\mathrm{B}=$ unstandardized regression coefficient; $\mathrm{SE}=$ standard error; Rect. Area = rectangular area of displacement; EODL $=$ eyes-open, double-leg stance; ECDL = eyes-closed, double-leg; EOSL = eyes-open, single-leg; ECSL = eyes-closed, single-leg.

pressure at week six or week seven. The TM group was significantly in higher heart rate at week six, but there was no significant difference by week seven. Adjustment for our protocol change (order effect) had no effect on any outcome.

\section{DISCUSSION}

\section{Immediate Treatment Effects}

This study examined the effects of six weekly 60-minute, full-body TM treatments compared to a resting control group on balance, nervous system, and cardiovascular measures in healthy, older adults. The immediate treatment effects at week six were assessed pre- and post-treatment in order to examine potential increases in instability immediately after a TM treatment (Table 3). As with study one which assessed these changes at week one, no increase in instability occurred immediately after TM. Increased instability would have suggested that additional safety measures should be utilized, especially with older adults who tend to have decreased postural stability ${ }^{(17)}$. There was a tendency for increased means in the balance measures, suggesting some participants may be more unstable after the treatment. These results support what is seen clinically, and suggest current safety measures are appropriate and should be continued. Adjusted means for diastolic blood pressure were higher immediately after the TM in the treatment group compared to the control group, with no differences in other cardiovascular measures. No differences between groups were found in these measures 
TABle 5. Analyses of Covariance Predicting Outcomes 60 Minutes Post-TM (Adjusted for Baseline) at Week 6

\begin{tabular}{lccccc}
\hline & \multicolumn{2}{c}{ Treatment } & \multicolumn{2}{c}{ Control } \\
\cline { 2 - 5 } & Adj.M & $S E$ & Adj.M & $S E$ & $F$ \\
\hline Reflex Variables & & & & & \\
PRD 2L & 64.5 & 3.99 & 68.9 & 5.53 & 0.40 \\
RI 2L & 57.1 & 3.75 & 52.1 & 5.06 & 0.62 \\
PRD 1L & 66.5 & 2.74 & 63.4 & 3.80 & 0.44 \\
RI 1L & 74.5 & 2.56 & 72.0 & 3.58 & 0.31 \\
$\mathrm{H}_{\max } / \mathrm{M}_{\max }$ & 0.19 & 0.02 & 0.30 & 0.03 & $11.6^{\mathrm{a}}$ \\
\hline
\end{tabular}

${ }^{\mathrm{a}} p<.05$

Adj. $\mathrm{M}=$ covariate adjusted mean (baseline as covariate); $\mathrm{SE}=$ standard error; $\mathrm{H}_{\max }=$ maximum Hoffman-reflex; $\mathrm{M}_{\max }=$ maximum M-wave; PRD 2L = paired reflex depression 2 leg; $P R D$ 1L = paired reflex depression 1 leg; RI 2L = recurrent inhibition 2 leg; RI 1L = recurrent inhibition 1 leg.

TABLE 6. Results of Pearson's Correlation Comparisons of H-reflex and Postural Control Measures (Pearson's $r$ ) Week 6

\begin{tabular}{cccc}
\hline \multirow{3}{*}{ Variable } & Baseline & Post-Treatment \\
\cline { 2 - 4 } & $\begin{array}{c}\text { RI } \\
\text { 1-leg }\end{array}$ & $\begin{array}{c}\text { PRD } \\
\text { 1-leg }\end{array}$ & $\begin{array}{c}\text { RI } \\
\text { 1-leg }\end{array}$ \\
\hline
\end{tabular}

Area Rect. EODL

Area Rect. ECDL

Area Rect. EOSL

$0.53^{\mathrm{a}}$

$-0.57^{\mathrm{b}}$

Area Rect. ECSL

$\mathrm{V}_{\text {Avg }}$ EODL

$\mathrm{V}_{\text {Avg }}$ ECDL

$\mathrm{V}_{\text {Avg }}$ EOSL

$-0.58^{\mathrm{b}}$

$\mathrm{V}_{\text {Avg }}$ ECSL

$-0.46^{\mathrm{a}} \quad-0.44^{\mathrm{a}}$

${ }^{\mathrm{a}} p<.05$

${ }^{\mathrm{b}} p<.01$

Area Rect $=$ area rectangular; $\mathrm{V}_{\mathrm{Avg}}=$ average velocity; $\mathrm{PRD}=$ paired reflex depression; RI = recurrent inhibition; EODL = eyes-open double-leg; ECDL = eyes-closed double-leg; EOSL = eyes-open single-leg; ECSL = eyes-closed single-leg.

in study one. Most studies indicate a decrease in cardiovascular measures after $\mathrm{TM}^{(28,39-40)}$. However, the timing of the readings in relation to the treatment is often not noted and may be a factor. Figure 3(c) indicates the change in systolic blood pressure over time (diastolic was similar). Thus, the timing of the measurements could strongly influence the results.

\section{Week Six Short-Term Post-Treatment Effects Across Time}

Treatment effects on balance and cardiovascular measures were assessed immediately post-TM to 60
TABLE 7. Fixed Effects Estimates of Cardiovascular Outcomes

\begin{tabular}{|c|c|c|c|}
\hline & \multicolumn{3}{|c|}{ Short-Term: Week 6} \\
\hline & $B$ & $S E$ & $t$ \\
\hline \multicolumn{4}{|l|}{ Systolic BP } \\
\hline Intercept & 41.7 & 12.7 & $3.27^{\mathrm{b}}$ \\
\hline Time & 1.02 & 1.60 & 0.63 \\
\hline Treatment & 3.51 & 4.27 & 0.82 \\
\hline Baseline & 0.67 & 0.09 & $7.17^{\mathrm{c}}$ \\
\hline Treatment $*$ Time & -4.24 & 1.96 & $-2.17^{a}$ \\
\hline \multicolumn{4}{|l|}{ Diastolic BP } \\
\hline Intercept & 10.6 & 6.15 & 1.72 \\
\hline Time & 0.45 & 0.88 & 0.51 \\
\hline Treatment & 5.65 & 2.18 & $2.58^{\mathrm{a}}$ \\
\hline Baseline & 0.84 & 0.07 & $11.2^{\mathrm{c}}$ \\
\hline Treatment $*$ Time & -2.31 & 1.08 & $-2.13^{a}$ \\
\hline \multicolumn{4}{|l|}{ Heart Rate } \\
\hline Intercept & 18.7 & 5.70 & $3.27^{\mathrm{b}}$ \\
\hline Time & -0.55 & 0.66 & -0.82 \\
\hline Treatment & 0.10 & 2.32 & 0.04 \\
\hline Baseline & 0.65 & 0.08 & $8.19^{c}$ \\
\hline Treatment $*$ Time & 0.89 & 0.81 & 1.10 \\
\hline
\end{tabular}

${ }^{\mathrm{a}} p<.05$

${ }^{\mathrm{b}} p<.01$

${ }^{c} p<.001$

$\mathrm{B}=$ unstandardized regression coefficient; $\mathrm{SE}=$ standard error; $\mathrm{BP}=$ blood pressure .

minutes post-TM to determine any differences that occur the 60 minutes after a treatment. Differences in the measures across time would also suggest that researchers should note specifically when measures are taken in order to assist in comparisons between studies and to further our understanding of treatment effects.

Short-term treatment effects on rectangular area and displacement velocity during week six revealed significant downward trajectories relative to controls from immediate post-treatment to 60 minutes post-treatment in several of the stances (Figures 3(a) and (b), Table 4). The eyes-open, single-leg and eyes-closed, double-leg stances seemed to provide an appropriate challenge without being too difficult for the participants to complete. The eyes-open, double-leg stance may have not have provided enough challenge; while the eyesclosed, single-leg stance proved to be too difficult. Together, these findings suggest an increase in postural stability through the 60-minute test period after TM when compared to the control group.

Nervous system measures (Table 5) were taken preTM and 60 minutes post-TM only, and at the same time points for the control group. These measures revealed a significantly lower adjusted mean in $\mathrm{H}_{\max } / \mathrm{M}_{\max }$ ratio 60 minutes in the treatment group compared to 
TABle 8. Results of Analyses of Covariance Predicting Week 6 and Week 7 Outcomes (Adjusted for Week 1 Baseline)

\begin{tabular}{|c|c|c|c|c|c|c|c|c|c|c|}
\hline & \multicolumn{5}{|c|}{ Week 6 Outcomes } & \multicolumn{5}{|c|}{ Week 7 Outcomes } \\
\hline & \multicolumn{2}{|c|}{ Treatment } & \multicolumn{2}{|c|}{ Control } & \multirow[b]{2}{*}{$F$} & \multicolumn{2}{|c|}{ Treatment } & \multicolumn{2}{|c|}{ Control } & \multirow[b]{2}{*}{$F$} \\
\hline & Adj.M & $S E$ & Adj.M & $S E$ & & Adj.M & $S E$ & Adj.M & $S E$ & \\
\hline \multicolumn{11}{|c|}{ Motoneuron Pool Excitability } \\
\hline PRD2 & 62.0 & 4.27 & 57.0 & 5.91 & 0.46 & 64.4 & 4.23 & 68.1 & 5.99 & 0.25 \\
\hline RI2 & 51.1 & 7.11 & 58.4 & 9.82 & 0.37 & 76.1 & 2.93 & 79.5 & 4.15 & 0.47 \\
\hline PRD1 & 61.3 & 4.38 & 60.9 & 6.08 & 0.01 & 72.0 & 3.63 & 65.7 & 5.14 & 1.00 \\
\hline RI1 & 71.9 & 7.54 & 70.5 & 10.4 & 0.01 & 82.2 & 3.26 & 72.6 & 4.62 & 2.82 \\
\hline $\mathrm{H}_{\max } / \mathrm{M}_{\max }$ & 0.25 & 0.02 & 0.29 & 0.03 & 1.05 & 0.22 & 0.02 & 0.22 & 0.03 & 0.01 \\
\hline \multicolumn{11}{|l|}{ Postural Control } \\
\hline \multicolumn{11}{|c|}{ Displacement Area } \\
\hline Rect.: EODL & 0.58 & 0.14 & 0.60 & 0.21 & 0.01 & 0.46 & 0.11 & 1.16 & 0.18 & $10.3^{\mathrm{b}}$ \\
\hline Rect.: ECDL & 0.74 & 0.08 & 0.76 & 0.12 & 0.02 & 0.59 & 0.10 & 1.25 & 0.18 & $9.59^{b}$ \\
\hline Rect.: EOSL & 1.51 & 0.26 & 1.25 & 0.38 & 0.33 & 1.35 & 0.22 & 1.61 & 0.37 & 0.33 \\
\hline Rect.: ECSL & 5.21 & 1.35 & 6.89 & 2.02 & 0.47 & 4.06 & 0.30 & 3.08 & 0.49 & 2.82 \\
\hline \multicolumn{11}{|c|}{ Displacement Velocity } \\
\hline Vel. : EODL & 0.67 & 0.08 & 0.67 & 0.12 & 0.01 & 0.58 & 0.09 & 1.08 & 0.15 & $7.54^{\mathrm{a}}$ \\
\hline Vel.: ECDL & 0.87 & 0.11 & 0.95 & 0.17 & 0.17 & 0.71 & 0.06 & 0.97 & 0.09 & $5.15^{\mathrm{a}}$ \\
\hline Vel.: EOSL & 1.87 & 0.14 & 1.62 & 0.20 & 1.06 & 1.49 & 0.08 & 1.88 & 0.13 & $6.56^{\mathrm{a}}$ \\
\hline Vel.: ECSL & 2.49 & 0.35 & 2.55 & 0.53 & 0.01 & 2.42 & 0.29 & 1.90 & 0.50 & 0.81 \\
\hline \multicolumn{11}{|l|}{ Cardiovascular } \\
\hline Systolic BP & 127.8 & 3.10 & 128.9 & 4.48 & 0.04 & 121.4 & 3.06 & 136.6 & 4.56 & $7.63^{b}$ \\
\hline Diastolic BP & 75.7 & 1.67 & 77.6 & 2.42 & 0.41 & 76.5 & 1.73 & 78.2 & 2.52 & 0.31 \\
\hline Heart Rate & 76.1 & 2.02 & 67.7 & 2.92 & $5.60 *$ & 71.0 & 2.13 & 69.0 & 3.18 & 0.26 \\
\hline
\end{tabular}

${ }^{\mathrm{a}} p<.05$

${ }^{\mathrm{b}} p<.01$

Adj.M = covariate adjusted mean (week 1 baseline as covariate); $\mathrm{SE}=$ standard error; Rect. = rectangular area of displacement; PRD 2L = paired reflex depression 2 leg; PRD 1L = paired reflex depression 1 leg; RI 2L = recurrent inhibition 2 leg; RI 1L= recurrent inhibition 1 leg; EODL = eyes-open, double-legged stance; ECDL = eyes-closed, double-legged; EOSL = eyes-open, single-legged; ECSL = eyes-closed, single-legged; $\mathrm{BP}=$ blood pressure.

the control group; no differences in the other nervous system measures were revealed. This decrease was of the same magnitude as found in part one of this study, indicating that the additional 6 weeks of treatment did not influence the pre- to post-TM effects of the single session. $\mathrm{H}_{\max }$ indicates how much of the motoneuron pool is recruited during testing, compared to $M_{\max }$ which represents full recruitment of the motoneuron pool. Thus, the $\mathrm{H}_{\max } / \mathrm{M}_{\max }$ ratio indicates the proportion of the motoneuron pool that is recruited during testing ${ }^{(37)}$. The $\mathrm{H}_{\max } / \mathrm{M}_{\max }$ ratio decrease suggests the treatment had a physiological effect on the neuromuscular system, with fewer motoneurons recruited during a contraction. This may be influenced by training, injury, treatments or other factors. A lower adjusted mean $\mathrm{H}_{\max } / \mathrm{M}_{\max }$ ratio in the treatment group could indicate a decrease in muscle fatigue compared to the control group; however, more work would need to be completed to quantify muscle fatigue after TM.
Cardiovascular measures of systolic and diastolic blood pressure also followed a significant decreasing trajectory from immediate post-treatment to $60 \mathrm{~min}$ utes post-treatment in the treatment group compared to the control group (Figure 3(c), Table 7). This decrease was expected and has been previously reported ${ }^{(28,39)}$. Interestingly, no changes in heart rate were found. While the effect of TM on cardiovascular measures and blood flow has been reported, some results are conflicting ${ }^{(28,30,40)}$. Additional research on these effects and mechanisms behind these changes is needed and may reveal a potential for TM as a nonpharmaceutical treatment for elevated blood pressure. It must be kept in mind that individuals may respond differently to TM, as they do to medications. An individual uncomfortable with touch may not respond with a decreased blood pressure. Blood pressure medications all have possible side effects and interactions with other medications, vitamins, and food including increased 

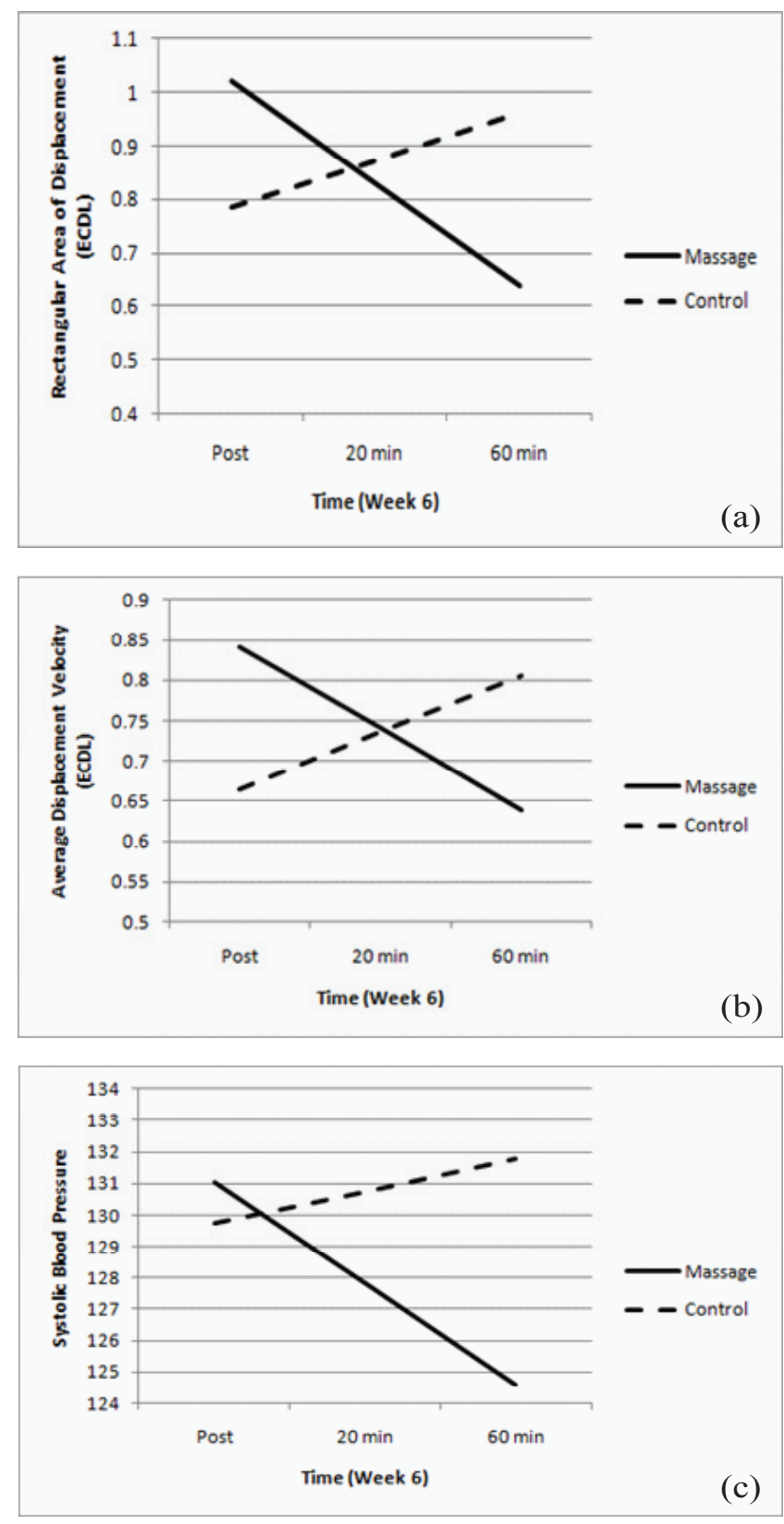

FIGURE 3. Short term post-treatment postural control displacement (a), velocity (b), and systolic blood pressure (c) trajectories at week 6 (measure across time: 0, 20 and 60 min time points).

Post $=$ measures taken immediately after the TM session; $20=$ 20 minutes after TM session; $60=60$ minutes after TM; EODL = eyes-open double-leg; $E C D L=$ eyes-closed double-leg; solid line = treatment group; dashed line $=$ control group.

urination, sexual effects, weakness, leg cramps, fatigue, asthma, depression, sleep issues, skin rash, loss of taste, cough, and other concerns ${ }^{(41)}$. Clearly, any intervention must consider the individual as a whole and develop the best possible combination of treatments for the health and wellness of the patient.

Further assessment of most measures revealed an increase in the control trajectories from immediate post- to 60 minutes post-treatment. This is confirmed by looking at the raw means in Table $2(\mathrm{~b}-\mathrm{c})$. This may be a fatigue factor caused by the long study period required for pretesting, resting for an hour, and then repeating the testing three times post-treatment through the 60-minute time period. Treatment group participants completed the same protocols; however, they received the TM which may have influenced any fatigue factor.

\section{Long-Term Treatment Effects: Week Six and Seven}

The long-term effects of the treatment were compared to the control condition on balance, nervous system, and cardiovascular measures at the pretreatment time point for week six and at week seven (Table 8). Week seven was a follow-up, non-treatment week with all participants coming in for testing only.

Assessment of balance at week six indicated no significant differences between the treatment and control groups. However, by week seven there were significantly lower values in the treatment group for rectangular displacement area and velocity in several stance conditions, suggesting an improved ability to maintain balance at week 7 . This result, and the timing of the benefits of TM, is an interesting finding worthy of further investigation.

Although short-term changes after treatment in motoneuron pool excitability were evident, analysis of the reflex data (Table 8) revealed no significant longterm changes at week six or week seven. Single-leg RI, which would be more likely to demonstrate longterm influences, did approach significance $(\mathrm{F}=2.82$, $p=.10)$ at week seven. The lack of long-term effects on reflex variables is consistent with what we know about how reflexes function. Spinal reflexes provide the body with an immediate response to environmental change (internal and external). This study design looked for simple changes in reflex response after long-term treatment. It may be that to determine the influence of TM on spinal reflexes, a better design would be to assess reflex response to challenges before and after treatment. This will be a focus of future work.

Long-term cardiovascular measures again revealed no significant differences at week six; however, by week seven there were significantly lower systolic blood pressures in the treatment group compared to baseline controls. No differences were found in diastolic blood pressure at either week compared to baseline controls. Interestingly, heat rate was higher week six for the treatment group, but there were no differences found at week seven. Clearly, more work needs to be done to understand the influence of weekly TM on cardiovascular measures, and to determine if the timing of the tests influences the results.

The immediate effects at week six were similar to a previous study in our lab (in press) analyzing the effects of a single session of TM. It may be that the 
pre- to post-treatment effects of TM are immediate and consistent across time. It may also be that longterm benefits are perhaps just beginning to occur after six weekly treatments. The changes after seven weeks were fairly robust, making longer studies to investigate these effects over time warranted. It is also interesting to note that these changes were found after one week of nontreatment. Research investigating how long any treatment effects are maintained should be undertaken. A recent study assessed eight weeks of TM for knee osteoarthritis, with a follow-up study to establish an optimal TM dose ${ }^{(42)}$. Few other studies assessing long-term effects of massage have been conducted ${ }^{(43-44)}$. Clearly more work needs to be completed in this area. Finally, it should be noted that the effects of most medications are short-term, and end once the patients stops taking the medication. Any extended effects of TM would suggest that this treatment should be considered along with, or in place of, standard medical interventions.

Limitations of this study include the use of healthy, older participants; results may differ with individuals experiencing conditions common with aging such as osteoarthritis, high blood pressure or diabetes. Our participants were an average of 62.9 years of age, making them young on the spectrum of older adults. Also, our participants self-selected to join our study. While posters and word of mouth were used to access all ranges of the older population, it is anticipated that those that were more healthy and with previous positive touch experiences were more likely to volunteer. This was an introductory study and results may vary with a less healthy or older population; a larger study should be conducted to include a wider range or older adults. Additionally, the control group simply rested between testing session rather than receiving a treatment, and completed daily activities as usual. Use of an alternative treatment would provide interesting comparisons. If research can show that TM produces improvements in balance, nervous system, and cardiovascular measures which increase over time and are maintained after therapy ceases, this would be a substantial finding strongly promoting this treatment as a nonpharmaceutical intervention for falls in older adults.

\section{CONCLUSION}

A single session of TM produced an immediate postsession elevation in diastolic blood pressure and no increase in postural instability compared to the controls. From immediate post-treatment to 60minute follow-up, displacement area/velocity and blood pressure decreased in the TM group at week six. Long-term benefits of TM at week seven were detected in displacement area/velocity and systolic blood pressure. Results suggest six weeks of TM resulted in immediate and long-term improvements in stability and blood pressure in older, healthy adults.

\section{ACKNOWLEDGMENTS}

The authors would like to thank the Massage Therapy Foundation for providing funding for this research. The authors would also like to thank the massage therapists involved in this study: Diane Hanson, Wanda Henderson, and Sara Samuelson.

\section{CONFLICT OF INTEREST NOTIFICATION}

The authors declare there are no conflicts of interest.

\section{COPYRIGHT}

Published under the CreativeCommons AttributionNonCommercial-NoDerivs 3.0 License.

\section{REFERENCES}

1. Vellas BJ, Wayne SJ, Romero LJ, et al. Fear of falling and restriction of mobility in elderly fallers. Age Ageing. 1997;26(3):189-193.

2. Englander F, Hodson TJ, Terregrossa RA. Economic dimensions of slip and fall injuries. J Forensic Sci. 1996;41(5):733-746.

3. Blank WA, Freiberger E, Siegrist M, et al. interdisciplinary intervention to prevent falls in community-dwelling elderly persons: protocol of a cluster-randomized trial [PreFalls]. BMC Geriatr. 2011;11:7.

4. Dejaeger E. Falls in the elderly. A need for a general intervention [in Dutch]. Tijdschr Gerontol Geriatr. 2005;36(4):136-137.

5. Faddis MN, Rich MW. Pacing interventions for falls and syncope in the elderly. Clin Geriatr Med. 2002;18(2):279-294.

6. Gillespie LD, Gillespie WJ, Robertson MC, et al. Interventions for preventing falls in the elderly. Cochrane Database Syst Rev. 2003, Issue 4. Art.Nb.CD000340.

7. Gu MO, Jeon MY, Kim HJ, et al. A review of exercise interventions for fall prevention in the elderly [in Korean]. Taehan Kanho Hakhoe Chi. 2005;35(6):1101-1112.

8. Hendriks MR, van Haastregt JC, Diederiks JP, et al. Effectiveness and cost-effectiveness of a multidisciplinary intervention programme to prevent new falls and functional decline among elderly persons at risk: design of a replicated randomised controlled trial [ISRCTN64716113]. BMC Public Health. 2005;5:6.

9. Larsson L, Ramamurthy B. Aging-related changes in skeletal muscle. Mechanisms and interventions. Drugs Aging. 2000;17(4):303-316.

10. Neyens JC, van Haastregt JC, Dijcks BP, et al. Effectiveness and implementation aspects of interventions for preventing falls in elderly people in long-term care facilities: a systematic review of RCTs. J Am Med Dir Assoc. 2011;12(6):410-425.

11. Nikolaus T, Bach M. Preventing falls in community-dwelling frail older people using a home intervention team (HIT): 
results from the randomized Falls-HIT trial. J Am Geriatr Soc. 2003;51(3):300-305.

12. Zhang JG, Ishikawa-Takata K, Yamazaki H, et al. The effects of Tai Chi Chuan on physiological function and fear of falling in the less robust elderly: an intervention study for preventing falls. Arch Gerontol Geriatr. 2006;42(2):107-116.

13. Harwood RH, Foss AJ, Osborn F, et al. Falls and health status in elderly women following first eye cataract surgery: a randomised controlled trial. Br J Ophthalmol. 2005;89(1):53-59.

14. Johnson CB. Falls in the elderly. UCSF Division of Geriatrics Primary Lecture Series. San Francisco, CA: UCSF; 2001. PowerPoint presentation available from: www.ucop.edu/agrp/ docs/sf_falls.ppt

15. Patel JC. Falls in elderly. Indian J Med Sci. 2000;54(8): 350-352.

16. The prevention of falls in later life. A report of the Kellogg International Work Group on the Prevention of Falls by the Elderly. Dan Med Bull. 1987;34 Suppl 4:1-24.

17. Tinetti ME, Speechley M, Ginter SF. Risk factors for falls among elderly persons living in the community. $N$ Engl J Med. 1988;319(26):1701-1707.

18. Davies AJ, Kenny RA. Falls presenting to the accident and emergency department: types of presentation and risk factor profile. Age Ageing. 1996;25(5):362-366.

19. Richardson JK, Ashton-Miller JA. Peripheral neuropathy: an often-overlooked cause of falls in the elderly. Postgrad Med. 1996;99(6):161-172.

20. Wolfson LI, Whipple R, Amerman P, et al. Gait and balance in the elderly. Two functional capacities that link sensory and motor ability to falls. Clin Geriatr Med. 1985;1(3):649-659.

21. Allain H, Bentue-Ferrer D, Polard E, et al. Postural instability and consequent falls and hip fractures associated with use of hypnotics in the elderly: a comparative review. Drugs Aging. 2005;22(9):749-765.

22. Allcock LM, O'Shea D. Diagnostic yield and development of a neurocardiovascular investigation unit for older adults in a district hospital. $J$ Gerontol A Biol Sci Med Sci. 2000;55(8):M458-M462.

23. Hass CJ, Waddell DE, Wolf SL, et al. Gait initiation in older adults with postural instability. Clin Biomech (Bristol, Avon). 2008;23(6):743-753.

24. Laughton CA, Slavin M, Katdare K, et al. Aging, muscle activity, and balance control: physiologic changes associated with balance impairment. Gait Posture. 2003;18(2):101-108.

25. Silsupadol P, Lugade V, Shumway-Cook A, et al. Trainingrelated changes in dual-task walking performance of elderly persons with balance impairment: a double-blind, randomized controlled trial. Gait Posture. 2009;29(4):634-639.

26. Gu MO, Jeon MY, Eun Y. The development \& effect of a tailored fall prevention exercise for older adults [in Korean]. Taehan Kanho Hakhoe Chi. 2006;36(2):341-352.

27. Duval C, Lafontaine D, Hebert J, et al. The effect of Trager therapy on the level of evoked stretch responses in patients with Parkinson's disease and rigidity. J Manipulative Physiol Ther. 2002;25(7):455-464.

28. Moyer CA, Rounds J, Hannum JW. A meta-analysis of massage therapy research. Psychol Bull. 2004;130(1):3-18.

29. Durkin JL, Harvey A, Hughson RL, et al. The effects of lumbar massage on muscle fatigue, muscle oxygenation, low back discomfort, and driver performance during prolonged driving. Ergonomics. 2006;49(1):28-44.

30. Sefton JM, Yarar C, Berry JW, et al. Therapeutic massage of the neck and shoulders produces changes in peripheral blood flow when assessed with dynamic infrared thermography. $J$ Altern Complement Med. 2010;16(7):723-732.

31. Sefton JM, Yarar C, Pasco DD. Effect of therapeutic massage on peripheral blood flow as assessed by skin temperature measures in the neck and shoulders. J Altern Complement Med. 2010;16(7):723-32.

32. Sefton JM, Yarar C, Carpenter Dm, et al. Physiological and clinical changes after therapeutic massage of the neck and shoulders. Manual Ther. 2011;16(5):487-94.

33. Hedeker D, Gibbons R, Waternaux C. Sample size estimation for longitudinal designs with attrition: comparing timerelated contrasts between two groups. J Edu Behav Stats. 1999;24(1):70-93.

34. Sefton JM, Yarar C, Berry JW. Massage therapy produces short term improvements in balance, neurological and cardiovascular measures in older persons. Int J Ther Mass Bodywork. 2012. In press.

35. Sefton JM, Yarar C, Hicks-Little CA, et al. Six weeks of balance training improves sensorimotor function in individuals with chronic ankle instability. J Orthop Sports Phys Ther. 2011;41(2):81-89.

36. Sefton JM, Hicks-Little CA, Koceja DM, et al. Modulation of soleus H-reflex by presynaptic spinal mechanisms during varying surface and ankle brace conditions. Neurophysiol Clin . 2007;37(1):15-21.

37. Palmieri R, Ingersoll CD, Hoffman MA. The Hoffmann reflex: methodologic considerations and applications for use in sports medicine and athletic training research. $J$ Athl Train. 2004;39(3):268-277.

38. Sefton JM, Hicks-Little CA, Hubbard TJ, et al. Segmental spinal reflex adaptations associated with chronic ankle instability. Arch Phys Med Rehabil. 2008;89(10):1991-1995.

39. Kaye AD, Kaye AJ, Swinford J, et al. The effect of deep-tissue massage therapy on blood pressure and heart rate. J Altern Complement Med. 2008;14(2):125-128.

40. Weerapong P, Hume PA, Kolt GS. The mechanisms of massage and effects on performance, muscle recovery and injury prevention. Sports Med. 2005;35(3):235-256.

41. WebMD. Hypertension/High Blood Pressure Health Center. 2012. Available from: http://www.webmd.com/hypertensionhigh-blood-pressure/default.htm

42. Perlman AI, Ali A, Njike VY, et al. Massage therapy for osteoarthritis of the knee: a randomized dose-finding trial. PLoS One. 2012;7(2): $\mathrm{e} 30248$.

43. Bronfort G, Nilsson N, Haas M, et al. Non-invasive physical treatments for chronic/recurrent headache. Cochrane Database Syst Rev. 2004, Issue 3. Art.Nb. CD001878.

44. Kalichman L. Massage therapy for fibromyalgia symptoms. Rheumatology International. 2010;30(9):1151-1157.

Corresponding author: JoEllen $\mathrm{M}$. Sefton, $\mathrm{PhD}$, A.T.C., C.M.T., Department of Kinesiology, 2050 Memorial Coliseum, Auburn University, Auburn, AL 36849-5323, USA

Email: jmsefton@auburn.edu 